\title{
Laboreal
}

Volume 11 №2 | 2015

Varia

\section{Riesgos sociales del trabajo en turno largo : vida familiar y laboral en crisis en un campamento petrolero patagónico}

Riscos sociais do trabalho de turno de longa duração: vida familiar e vida no trabalho em crise num campo petrolifero na Patagónia

Risques sociaux du travail posté de longue durée : vie familiale et vie au travail en crise dans un champ pétrolier patagonique

Social risks of long shift work: work and family life in crisis in a Patagonian oil camp

\section{Jorge Walter}

\section{OpenEdition}

\section{Journals}

Edición electrónica

URL: http://journals.openedition.org/laboreal/3612

DOI: 10.4000/laboreal.3612

ISSN: 1646-5237

Editor

Universidade do Porto

Referencia electrónica

Jorge Walter, «Riesgos sociales del trabajo en turno largo : vida familiar y laboral en crisis en un campamento petrolero patagónico », Laboreal [En línea], Volume 11 №2 | 2015, Publicado el 01 diciembre 2015, consultado el 07 octubre 2019. URL : http://journals.openedition.org/laboreal/3612 DOI : 10.4000/laboreal.3612

Este documento fue generado automáticamente el 7 octubre 2019.

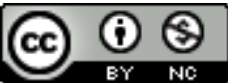

Laboreal está licenciado com uma Licença Creative Commons - Atribuição-NãoComercial 4.0 Internacional. 


\section{Riesgos sociales del trabajo en turno largo : vida familiar y laboral en crisis en un campamento petrolero patagónico}

Riscos sociais do trabalho de turno de longa duração: vida familiar e vida no trabalho em crise num campo petrolífero na Patagónia

Risques sociaux du travail posté de longue durée : vie familiale et vie au travail en crise dans un champ pétrolier patagonique

Social risks of long shift work: work and family life in crisis in a Patagonian oil camp

Jorge Walter

\section{NOTA DEL EDITOR}

http://dx.doi.org/10.15667/laborealxi0215jw

Manuscrito recibido en: septiembre /2015

Aceptado tras peritaje: Noviembre /2015

\section{Introducción}

1 Manuel García despertó temprano - en la reiterada pesadilla despedía en el aeropuerto a su hija recién nacida, a quien no volvería en las próximas dos semanas - y salió de la casilla rodante procurando no despertar a su compañero; disfrutó por un instante del imponente pero desolado, seco, muy ventoso y helado paisaje patagónico (muy conveniente, para despejar rápidamente el recuerdo de la mente) y desvió la mirada por enésima vez, sin poder evitarlo, hacia la "empresa de enfrente", mote que él y sus 
compañeros de las otras casillas utilizaban para referirse a las oficinas administrativas anexas al hotel donde se alojaba el personal jerárquico de la compañía multinacional.

Hacía 18 años que Manuel trabajaba para esa empresa, en la cual tenía actualmente a su cargo la coordinación de los supervisores de las obras realizadas por empresas locales contratadas. Pero Manuel no era un empleado de la empresa multinacional. Figuraba en su organigrama con un puesto jerárquico, pero su sueldo era pagado mensualmente por otra organización.

¿Por qué Manuel continuaba trabajando allí, tan lejos de su familia y a la vez tan demasiado - cerca de su compañero de trabajo en la pequeña casilla?, ¿Quiénes eran esos empleados que se desempeñaban en nombre de la empresa multinacional controlando las empresas contratadas a cargo de obras de construcción, siendo ellos mismos empleados de otra empresa contratada local?,¿A qué se debía su insatisfacción cuando comparaban su situación con "la empresa de enfrente"?

en 2011 a Manuel y sus colegas del Área de Proyectos al realizar una encuesta de percepciones sobre el funcionamiento del sistema de gestión de la seguridad de la empresa multinacional.

5 La protestas de Manuel y sus colegas sobre la calidad de vida en el campamento (en lo referido al alojamiento, la alimentación, las comunicaciones, el esparcimiento y la atención médica) nos invitaron a efectuar una revisión de la literatura sobre la calidad de vida y el trabajo en turnos largos gracias a la cual aprendimos que los mismos problemas que observábamos en el campamento se planteaban con especial agudeza en las plataformas petroleras offshore, donde la vida cotidiana y el trabajo tienen lugar en espacios confinados e incómodos y en lugares a menudo remotos, sometidos a las peores inclemencias climáticas.

6 El vínculo entre lo anterior y la subcontratación lo establecimos porque el problema nos fue planteado por el personal de la empresa a la cual pertenecía Manuel, que actuó como un revelador de lo que, luego supimos, era un problema de alcance mucho mayor.

\subsection{Cambios estructurales y riesgos psicosociales en la actividad petrolera}

7 Al igual que en las plataformas offshore, las actividades de perforación, extracción y transporte del petróleo y el gas que se realizan en tierra firme suelen requerir la creación de campamentos (es el nombre utilizado en el mundo petrolero, que alude a un carácter provisorio que en los hechos no poseen) para alojar al personal que trabaja en ellas.

8 En éste apartado tomaremos como referencia algunos trabajos que han realizado comparaciones entre los riesgos físicos y sobre todo psicosociales que afectan al personal que vive y trabaja en las plataformas offshore y en los campamentos onshore, dos realidades que, con sus similitudes y sus diferencias, se iluminan mutuamente.

9 La mayoría de esos trabajos, a los cuales nos referiremos a continuación, han sido reunidos en un informe de Katharine R. Parkes, del Departamento de Psicología Experimental de la Universidad de Oxford, que resume los resultados de nueve investigaciones realizadas entre 1996 y 2001 con financiamiento del Health and Safety Executive (HSE) del Reino Unido sobre los “Aspectos psicosociológicos del trabajo y la salud en la industria petrolera del Mar del Norte” (Parkes, 2002). 
10 En las conclusiones de una investigación sobre el trabajo por turnos (diurno/nocturno) realizado en 1990 y replicado en 1995 en una pequeña muestra ( $N=172)$ de trabajadores onshore y offshore se atribuyó el mayor incremento de la ansiedad y la mayor caída de la moral registradas en las instalaciones onshore a los cambios estructurales sucedidos a partir de mediados de la década de los años ochenta (reducciones de costos, reestructuraciones organizacionales), lo cual se debió a que "habían tenido lugar varios años antes en el ámbito offshore" (Parkes \& Razawi VI, 1996, p.5).

11 Cinco años después fue publicada una investigación comparativa realizada mediante una muestra mucho mayor de personas ( $\mathrm{N}=909)$ que trabajaban en cinco compañías en ocho sitios de tierra firme (Parkes \& Byron, 2001). Dicha investigación replicó un estudio realizado años antes en instalaciones offshore (Parkes \& Clark, 1997). El estudio incluyó factores físicos y psicosociales de estrés (trabajo por turnos, carga de trabajo, autonomía, variedad y claridad de la tarea), medidas y procedimientos de seguridad, satisfacción en el trabajo y perspectivas de trabajo futuro. Se evaluó la influencia del entorno (onshore/offshore), de la compañía y del tipo de tarea realizada. Nuevamente, la investigación reveló que el personal onshore estaba expuesto a una mayor carga de trabajo, realizado con menor autonomía y con menor satisfacción que el personal offshore. No llama entonces la atención que "Las medidas de ansiedad y de síntomas psicosomáticos (fuesen) significativamente más altas entre el personal onshore, tomando en cuenta los tipos de trabajo, las compañías, la edad y la personalidad neurótica" (Parkes \& Clark, 1997, p.29). Tampoco sorprenden los problemas de obesidad del personal más joven (índice de masa corporal superior a 30) sobre todo en el personal onshore $(12,7 \%)$ comparado con el personal offshore $(8,2 \%)$. Por último, los mayores problemas de sueño: 5,7 horas en promedio, contra 6,6 horas del personal offshore.

12 Esa mayor gravedad de los problemas contrastaba con el retraso en la consideración de los factores psicosociales en las instalaciones onshore de la industria petrolera que, según los resultados de nuestra propia investigación, continúa verificándose en la actualidad.

13 El principal entre los factores de riesgo psicosocial que afecta a los trabajadores petroleros (y de otras industrias que comparten este rasgo) es sin duda el trabajo en largos turnos de dos o tres semanas, con la consiguiente separación prolongada de la familias y el "síndrome del marido intermitente" (Morrice \& Taylor, 1978; Hubinger, Parker, \& Clavarino, 2002). Los problemas resultantes del trabajo por turnos largos ( $2 \mathrm{o}$ 3 semanas), extendidos ( 12 horas $\times 2$, vs. 8 horas $\times 3$ ) y nocturnos ha sido objeto de numerosos estudios específicos, particularmente en el ámbito onshore (Parkes, 2010).

14 Según la autora citada, ciertos rasgos del trabajo offshore "no aplican en el ámbito onshore". Menciona por ejemplo la exposición a un medio ambiente adverso - "afectado en las plataformas por el viento y los movimientos marinos"- o la localización en sitios remotos y aislados. Se refiere además a los problemas de alojamiento -cuando se comparten las cabinas, particularmente durante las horas de sueño (ronquidos) - si bien la insatisfacción más importante tiene que ver con "la dieta personal y los programas de actividad física", vinculados con el ya mencionado problema de la obesidad. Se suman a lo anterior los problemas de transporte (en el caso particular de las plataformas offshore se suman el miedo y el estrés provocado por los viajes en helicóptero), así como los riesgos de accidente de tránsito (debidos a los desajustes 
circadianos durante los cambios de turno (largo): "la readaptación toma típicamente 2 a 3 días").

15 Nuestras observaciones muestran sin embargo que los hallazgos sobre la incidencia de los factores mencionados en las instalaciones offshore tienen gran interés para el contexto onshore, así como "los hallazgos realizados por la literatura sobre el trabajo por turnos largos en el ámbito onshore proveen información relevante para la organización del tiempo de trabajo en el ámbito offshore" (Parkes, 2010, Executive summary). El trabajo por largos turnos, en lugares remotos y aislados, con un medio natural y un clima adversos, que plantean problemas de transporte, comunicación, esparcimiento, alimentación equilibrada (y alcoholismo), así como de convivencia en pequeñas comunidades cerradas, tienen un fuerte parecido con las condiciones que enfrentan los trabajadores que viven y trabajan en los campamentos patagónicos donde realizamos la investigación.

Tratándose de cambios estructurales y reorganizaciones empresarias con énfasis en la reducción de costos llama la atención, por último, que el tipo de vínculo contractual no fuese considerado - o solo circunstancialmente - en los trabajos comentados.

\subsection{De la tercerización de los riesgos a la cooperación con los subcontratistas}

17 La literatura internacional sobre el impacto de las reestructuraciones organizacionales en la gestión de la seguridad - registrado en los informes del apartado precedente puso de manifiesto que la tercerización, enfocada en la reducción de costos, acarreó desorganización del trabajo, precarización del empleo y una doble indefensión, legislativa y sindical de los trabajadores (Quinlan, Mayhew, \& Bohle, 2001; Rousseau \& Libuser, 1997) siendo comúnmente utilizada para transferir a empresas contratadas la responsabilidad por la realización las actividades más riesgosas (Tazi, 2010). No sorprende entonces el consiguiente fuerte incremento de los accidentes y su impacto sobre la salud de sus trabajadores (Mayhew, Quinlan, \& Ferris, 1997; Nenonen, 2011).

El fenómeno tuvo alcance global, pues involucró a países desarrollados y en vías de desarrollo. Estos últimos lo sufrieron en mayor medida - y reaccionaron más tardedebido a la debilidad estructural de sus mercados de trabajo: "there is good evidence that precarious employment is expanding in the third world ... where the informal sector typically accounts for over the half the workforce" (Quinlan et al. 2001) [1]. Tampoco sorprende entonces que, como consecuencia de lo anterior, se concibieran e implementaran luego en diferentes países - comenzando por los más desarrollados - normativas y sistemas públicos de control de los abusos en materia de contratación consistentes en consagrar la co-responsabilidad de los contratantes en los accidentes sucedidos en las empresas que contratan (Johnstone, Mayhew, \& Quinlan, 2005; Johnstone, 2005; Nossar, Johnstone, \& Quinlan, 2003). Fue así como, en ciertos países, sectores y empresas las tendencias iniciales negativas comenzaron lentamente a revertirse.

19 Así por ejemplo, la Ley 699/2003 apuntó en Francia "a reforzar la cooperación entre los directivos de las empresas contratantes y contratadas en cuanto a la gestión de los riesgos relativos a la co-actividad, atribuyendo "la gestión integral del riesgo industrial" al directivo principal de la empresa contratante. Dicha ley amplió los Comités de Higiene y Seguridad para integrar en ellos representantes de las empresas contratadas" (Cantero, 2008). A los dispositivos y restricciones previstos por ella 
(limitaciones a la subcontratación en cascada, establecimiento de planes de prevención, formación de Comités de Higiene, Seguridad y Condiciones de Trabajo... "y otras disposiciones reglamentarias tendientes a la corresponsabilidad") se sumó, en el caso particular de las plataformas petroleras de ese país estudiadas en la tesis doctoral de la cual tomamos estas informaciones, la constitución de "redes de proximidad" con las empresas contratadas en las plataformas (onshore), un proceso de especialización de los mismos y la creación de dispositivos formales e informales de coordinación y control interempresas en los sitios. Como consecuencia de lo anterior tuvo lugar "una reducción progresiva de la distancia entre las tasas de frecuencia de las empresas contratantes y las contratadas en el sector químico en general y en los cuatro sitios analizados en particular" (Cantero, 2008, p.266).

Otro cambio importante en materia de subcontratación involucró, por último, la índole de las actividades puestas a cargo de empresas contratadas. En efecto, “...la contratación evolucionó considerablemente durante las últimas dos décadas extendiéndose desde actividades sin valor agregado para los clientes, tales como el catering, el transporte o el cuidado de espacios verdes, hacia la subcontratación de soportes directos del negocio tales como el mantenimiento de las unidades de producción" (Tazi, 2010: 23). Este último cambio, y el comentado previamente en cuanto al surgimiento de formas de colaboración entre empresas contratantes y contratadas se verifican claramente, como veremos, en el caso analizado en la presente investigación.

\subsection{Metodología y materiales}

21 Mantendremos el anonimato de la empresa contratante utilizando una localización genérica (la enorme Patagonia argentino-chilena) y un nombre de fantasía (PDF) ya empleado en una anterior publicación a la cual nos referiremos más adelante.

La encuesta de la cual provienen los datos que presentaremos fue realizada con posterioridad a la implementación en la filial de un Sistema de Management de la Seguridad (SMS) según normas desarrolladas por la casa matriz [2]. Realizamos la encuesta en la filial patagónica por encargo de la propia empresa, interesada en indagar sobre la correspondencia entre la normativa certificada y las prácticas de gestión de la seguridad. Tanto la certificación, como la encuesta, fueron realizadas en todas las filiales de la firma a nivel internacional.

23 El diagnóstico se realizó mediante un diseño mixto, cuantitativo y cualitativo (Lee, 1999). Un cuestionario con 100 preguntas fue respondido durante la fase inicial cuantitativa por el $90 \%(\mathrm{~N}=1836)$ de los trabajadores permanentes de PDF y de las empresas contratadas que en ese momento realizaban tareas para la organización. En el caso de los gerentes, jefes y supervisores de PDF la tasa de respuesta fue del 100\%.

Las preguntas fueron agrupadas para su análisis según un conjunto de parámetros sobre aspectos referidos a los comportamientos individuales y grupales, la organización del trabajo y las prácticas directivas y de gestión. Tras análisis estadístico, la interpretación de los resultados fue discutida en entrevistas individuales y grupales (grupos focales) realizadas en los sitios de trabajo (sede corporativa y campamentos patagónicos) con la participación de personal de diferentes niveles jerárquicos, sectores, especialidades, antigüedad y formas de vinculación contractual. El objetivo de las entrevistas individuales y colectivas fue recabar interpretaciones y explicaciones 
contextualizadas para los resultados cuantitativos, información adicional y propuestas de solución para los problemas identificados. A tal efecto fueron convocados 37 grupos focales en 5 localizaciones diferentes, con un total de 143 personas entrevistadas. El presente artículo recurrirá sobre todo al material cualitativo, mediante un tratamiento sistemático de los testimonios recogidos en las entrevistas [3].

La encuesta no se aplicó a una muestra sino a la totalidad de los empleados presentes en la empresa - fuese personal propio o de empresas contratadas - en el momento de su realización, para que cumpliese con la doble función de instrumento de diagnóstico e involucramiento del personal (Walter, Poy, \& Darmohraj, 2009).

Sobre el total de cuestionarios completados y válidos, el $71,2 \%$ fue respondido por personal de empresas contratadas que trabajaba en ese momento para PDF.

Sobre el trabajo de campo

Iniciaremos la presentación del caso refiriéndonos a un factor cuya influencia descubrimos en durante la fase cualitativa de la investigación: el tipo particular de contrato que vinculaba con PDF al personal de un área clave de la empresa situada en el campamento patagónico donde observamos el fenómeno que nos motivó a escribir el artículo.

29 La razón por la cual elegimos dicha área para la realización de grupos focales fue entender el porqué de su desempeño excepcional en materia de seguridad, pues estaba a cargo de la supervisión de las obras realizadas por empresas locales pequeñas y medianas contratadas, un eslabón usualmente débil en materia de resultados de seguridad (Mayhew et al. 1997; Tazi, 2010). Por tal motivo también realizamos entrevistas individuales y colectivas a directivos, jefes, supervisores y operarios de dichas empresas en los sitios donde realizaban las obras.

El grupo focal que inspiró éste trabajo se reunió en la oficina del Área de Proyectos situada en un sector del campamento separado del hotel y los edificios administrativos principales de la empresa. En dicho sector estaban alojados, en casillas rodantes compartidas por dos personas, los miembros de la empresa contratada que constituían la mayoría del personal del sector, que en diversas ocasiones se refirieron irónicamente a "la empresa de enfrente" para enfatizar lo que consideraban un síntoma de la marginación del sector reflejado - entre otras cosas - en su ubicación [ [ ${ }^{4}$.

31 Dado el excelente desempeño del área, una de las informaciones que nos había sorprendido en el momento de organizar los grupos focales era el muy alto nivel de ansiedad registrado por la encuesta especialmente entre los miembros de la jerarquía, lo cual, sin embargo, no era un rasgo distintivo de ésta área en particular. Lo que verdaderamente no esperábamos fue la larga y detallada exposición de motivos que fue expuesta cuando efectuamos la pregunta sobre las razones que explicaban la ansiedad.

Los motivos de la ansiedad se referían, como veremos, a una serie de cuestiones respecto de las cuales los miembros del área se sentían menoscabados, relativas a la calidad de vida de los habitantes de esa parte del campamento. 


\section{El campamento patagónico de PDF y su Área de Gestión de Proyectos}

\subsection{Algunos antecedentes, a modo de presentación}

La empresa realizó las primeras inversiones en la región a comienzos de los años ochenta. En los inicios de la década siguiente realizamos una investigación sobre su forma de organizar la transferencia de tecnología para una gran obra de infraestructura onshore, a partir de la cual publicamos un artículo en el cual pusimos de manifiesto las virtudes de su política consistente en recurrir para el diseño de la ingeniería de detalle de dicha obra a empresas de ingeniería locales conocedoras de las normas y las redes domésticas de subcontratación (Walter, 2000).

34 A mediados de los años 2000 la empresa implementó en todas sus filiales un sistema de gestión de la seguridad desarrollado por la casa matriz y pocos años después realizamos la encuesta de percepciones sobre el funcionamiento del nuevo sistema en su filial patagónica. Es esa misma política consistente en recurrir a empresas de ingeniería locales por su conocimiento de las redes domésticas de subcontratación la que observamos aplicada ahora a la gestión de procesos centrales como la gestión de la seguridad y el mantenimiento.

\subsection{Las formas de contratación y la composición del personal}

El próximo cuadro lo construimos a partir de la información recogida por la encuesta y refleja la composición según categorías contractuales del personal que respondió el cuestionario: empleados permanentes de PDF, empleados de empresas contratadas por PDF, y entre éstas últimas, empleados de empresas contratistas de obras y "contratados de estructura".

Obsérvese el peso significativo del personal de empresas contratadas $(71,2 \%)$, y entre ellas, del personal "contratado de estructura" (31,6\%). Es menos llamativa la proporción de personal que trabajaba en las empresas a cargo de las obras (pues reflejaba en todo caso el dinamismo de las inversiones realizadas por PDF en ese momento). 
Cuadro 1: personas que trabajaban para PDF en el momento de la Encuesta (2011), según tipo de relación contractual.

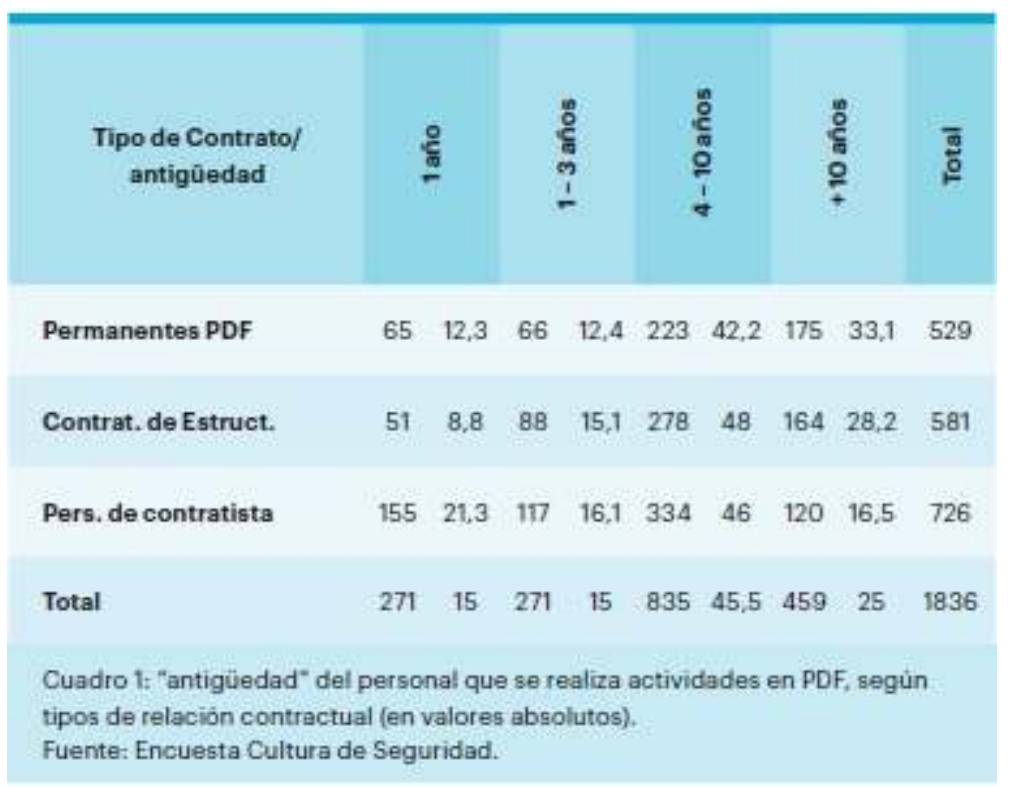

FUENTE: Encuesta Cultura de Seguridad.

La categoría contratados de Estructura PDF la asignaba al personal asalariado de una empresa contratada (que denominaremos MRI [5]) que se desempeñaba en PDF en forma permanente, ocupando en ella posiciones jerárquicas, es decir "de estructura", a cargo del mantenimiento y la supervisión de la seguridad en los trabajos realizados por las empresas contratadas para la realización de obras de construcción (como la instalación de equipos, cañerías, válvulas, etc.), para lo cual PDF les ofrecía a los empleados de MRI las mismas capacitaciones que impartía a su personal permanente.

Además de recibir las mismas capacitaciones, nos sorprendió descubrir que los Contratados de Estructura presentaban una distribución por "antigüedades" [ $\left.{ }^{6}\right]$ muy parecida a la del personal permanente de PDF (cuadro 2 del Anexo y gráfico 1 a continuación).

Gráfico 1: "antigüedad" del personal que trabaja para PDF, según tipos de relación contractual (en porcentajes)

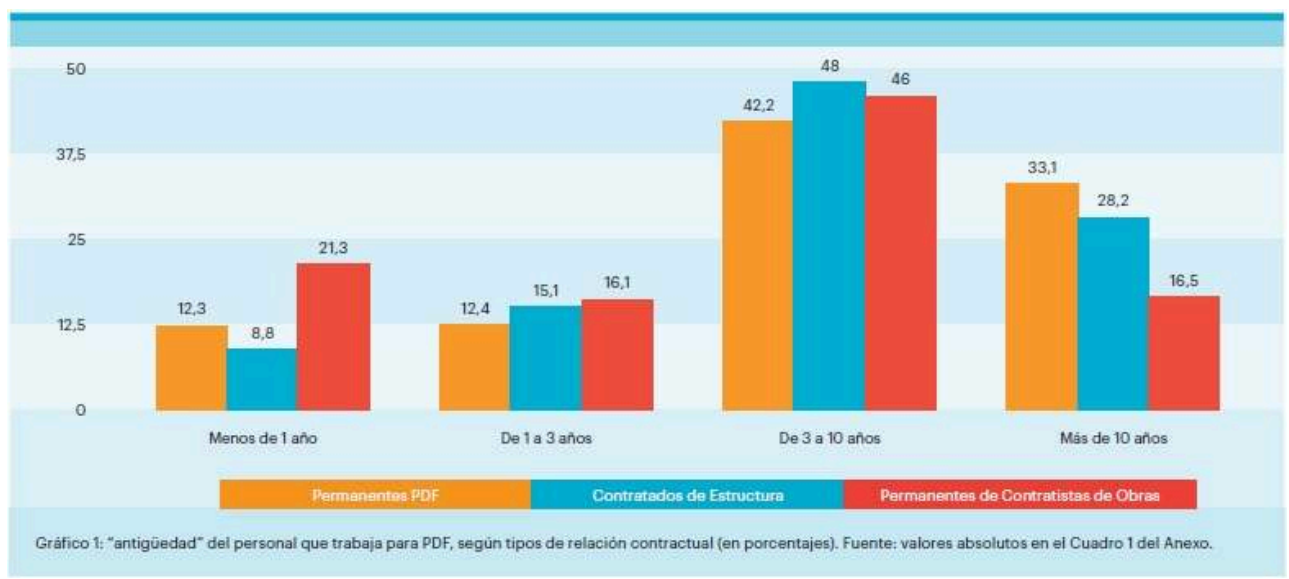

FUENTE: valores absolutos en el Cuadro 1 del Anexo. 
Como puede verse, algo parecido sucedía también con el personal de las empresas contratadas, lo cual se relaciona posiblemente con una dinámica propia del mercado de trabajo local: más del $40 \%$ de dicho personal llevaba entre 4 y 10 años realizando obras para PDF. Un Gerente permanente de PDF nos brindó la siguiente explicación: “Aunque cambie la empresa contratada su personal se mantiene. Cincuenta y cincuenta por ciento como mínimo es recontratada por la nueva empresa que se contrate, que con el cincuenta por ciento ya capacitado traslada su conocimiento al cincuenta por ciento de los nuevos".

\subsection{El rol de los contratados de estructura}

$$
\begin{aligned}
& \text { gestión de la seguridad llegaba hasta el nivel más alto pues uno de los dos Gerentes de } \\
& \text { Higiene, Seguridad y Medio Ambiente que figuraban en el organigrama de PDF era } \\
& \text { también un "contratado de estructura". }
\end{aligned}
$$

\subsection{El desempeño superior de la Gerencia de Proyectos de PDF}

de estructura del Área de Proyectos fue motivado por una serie de indicios recogidos en la fase cuantitativa de la investigación.

En primer lugar, en los análisis de información secundaria provista por la empresa con anterioridad a la realización de la encuesta observamos que sobre 12 ítems de control de la auditoría externa anual del sistema gestión de la seguridad, el ítem en el que 
mejor calificaba la filial era el referido al desempeño de los proveedores y las empresas contratadas para la realización de las obras.

En segundo lugar, la percepción de los riesgos por parte del personal con diferentes tipos de contrato relevada por la encuesta reveló que el personal permanente de PDF tenía una percepción más negativa (percibía generalmente los mismos riesgos en un nivel más alto) mientras que los contratados de estructura tenían sistemáticamente una percepción más positiva.

El buen desempeño de la filial en la relación con las empresas contratadas no solo se verificaba en una comparación interna con otros aspectos de la gestión de la seguridad (como el respeto de las reglas, la responsabilidad de los gerentes, las competencias y la formación del personal, el cuidado del medio ambiente, la preparación para situaciones de emergencia, el análisis de accidentes, etc.) sino, sobre todo, en una comparación con el desempeño de las empresas más importantes del mismo sector industrial en esos mismos aspectos.

En el próximo cuadro resumimos una serie de testimonios que dan cuenta de lo anterior recogidos en entrevistas a directivos y en grupos focales con supervisores, inspectores y operarios, tanto permanentes de PDF como contratados de estructura y, sobre todo, con personal contratado de diferentes niveles jerárquicos que trabajaba para una de las empresas contratistas locales (la Empresa C.) que realizaba obras para PDF desde hacía muchos años.

Cuadro 2: testimonios recogidos en entrevistas y grupos focales sobre el desempeño de PDF en seguridad comparado con otras empresas similares del sector

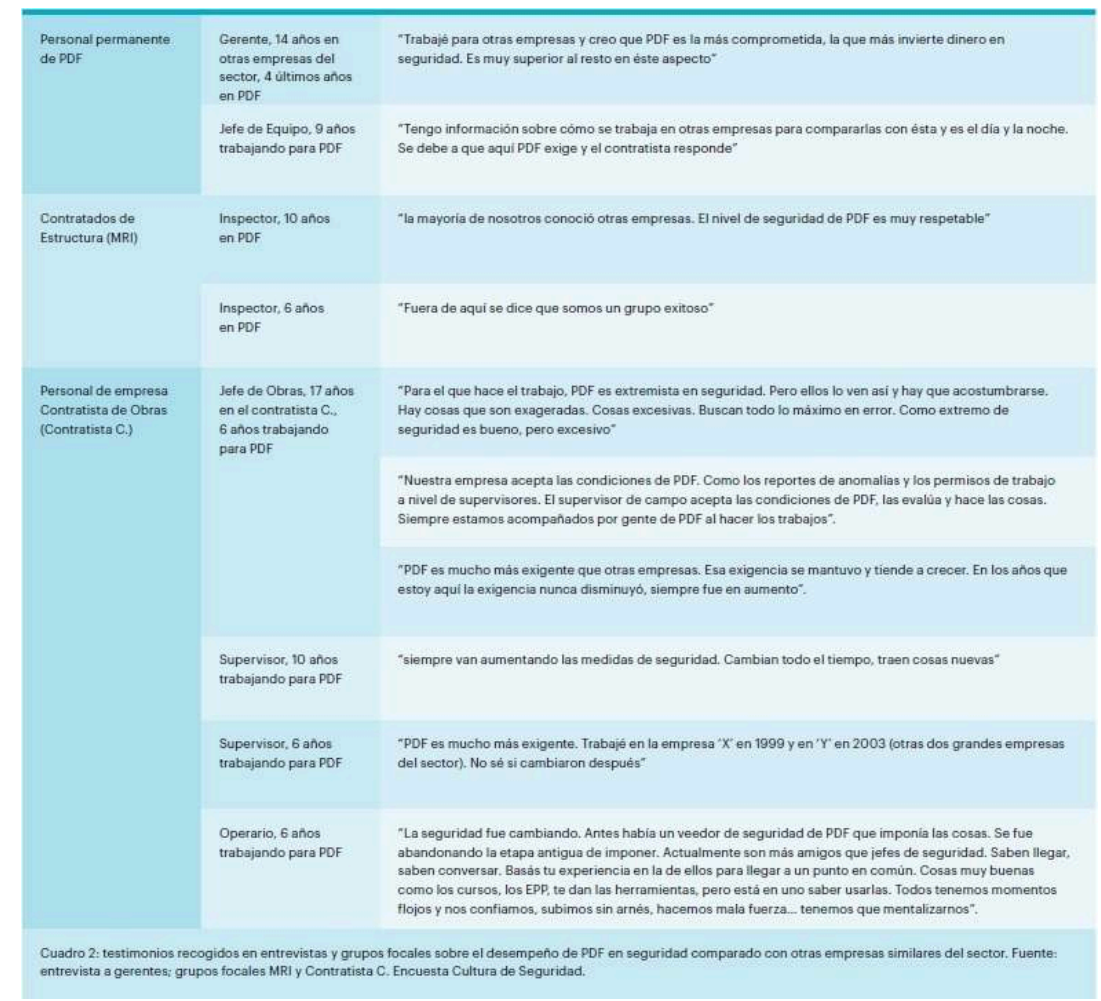

FUENTE: entrevista a gerentes; grupos focales MRI y Contratista C. Encuesta Cultura de Seguridad

La lectura del cuadro anterior pone de manifiesto que en todos los niveles de la jerarquía, y cualquiera sea el tipo de contrato, la percepción de los empleados con 
experiencia de trabajo en otras empresas del sector coloca sin excepción la gestión de la seguridad en PDF, y en la relación con las empresas contratadas, por encima del resto de las otras empresas de primer nivel del sector presentes en la región.

\subsection{La política de gestión de riesgos de la Gerencia de Proyectos}

Veamos ante todo la política de la Gerencia de Proyectos de PDF respecto al personal de empresas contratada que realizaban obras para la empresa. En el próximo cuadro presentamos una serie de testimonios del Director de Construcciones, empleado permanente de PDF con 17 años de experiencia en la empresa, que estaba a cargo de la Gerencia de Proyectos desde el momento de su creación.

Cuadro 3: la política de seguridad de la Gerencia de Proyectos de PDF vis-à-vis de las empresas contratistas de obras

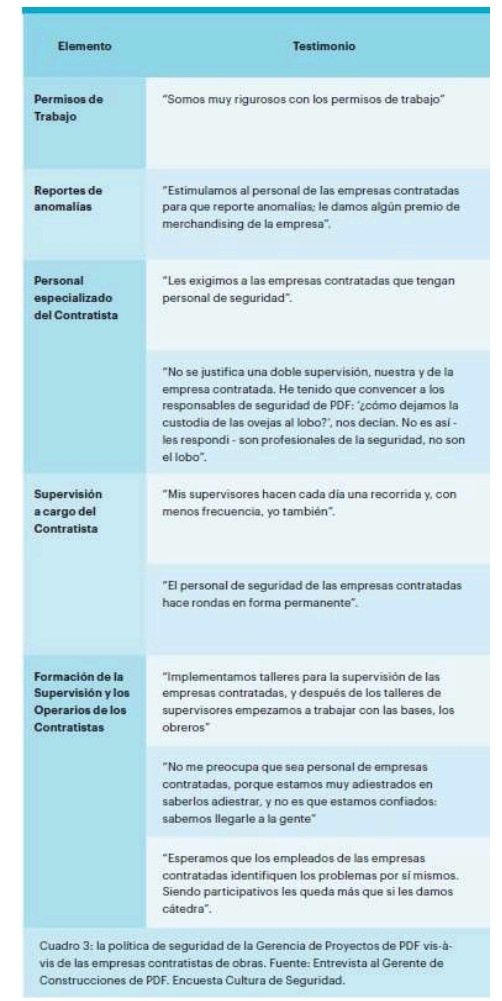

FUENTE: Entrevista al Gerente de Construcciones de PDF. Encuesta Cultura de Seguridad.

Según el testimonio del Director de Construcciones de PDF, la Gerencia de Proyectos de la empresa utilizaba con rigor una herramienta convencional de control de las empresas contratadas como los permisos de trabajo, pero esperaba además que dichas empresas se hiciesen cargo con autonomía - es decir, mediante personal propio - de la gestión de la seguridad en las obras a su cargo (como lo reconocía el operario de la empresa C. cuyo testimonio reportamos en el cuadro 2). Como contrapartida, los supervisores - los permanentes de PDF y los contratados de estructura - realizaban recorridas diarias, la Gerencia de Proyectos ofrecía apoyo a las empresas contratadas capacitando sus supervisores y operarios y estimulaba a sus operarios para que reportasen anomalías. Estas políticas, y en particular el hecho de confiar - apoyándolos para que desarrollen las capacidades necesarias - en la profesionalidad de las empresas 
contratadas constituían, sin embargo, en el seno de PDF, una política de seguridad distintiva de la Gerencia de Proyectos.

\subsection{Los contratados de estructura en la Gerencia de Proyectos} supervisores permanentes de PDF, así como con los supervisores y empleados de los contratistas, que pudiesen explicar la buena evaluación interna del desempeño de la Gerencia de Proyectos (por parte de la consultora que auditaba anualmente el sistema de gestión) y la reputación externa de PDF como una "escuela de seguridad" entre los contratistas del sector?

\section{siguientes testimonios sobre la cuestión que se resumen en el próximo cuadro.}

Cuadro 4: la "pata de conejo" de la gestión de la seguridad en las obras a cargo de empresas contratistas de obras

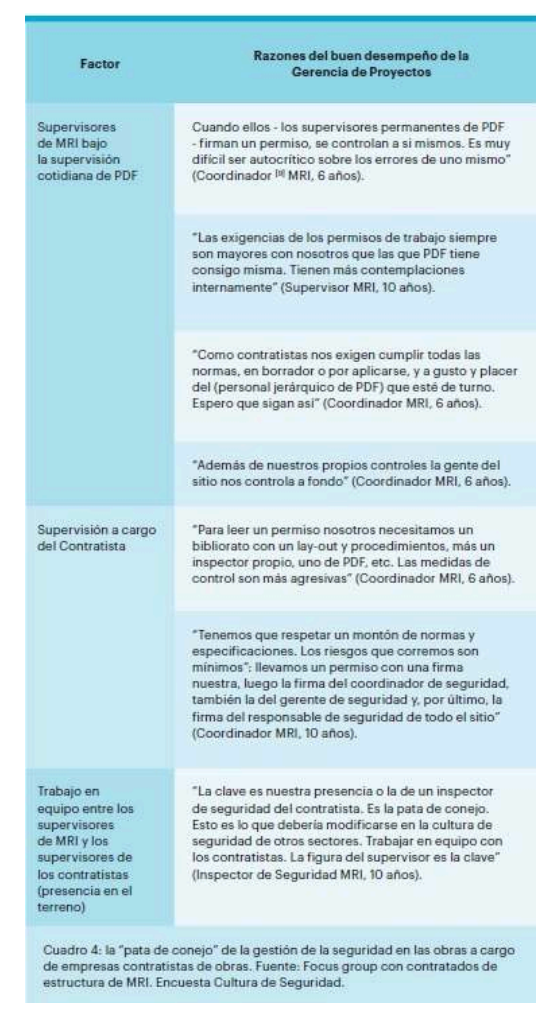

FUENTE: Focus group con contratados de estructura de MRI. Encuesta Cultura de Seguridad.

Los contratados de estructura de MRI, comenzando por el supervisor designado como coordinador general del grupo, consideraban entonces que la clave del buen desempeño de la Gerencia de Proyectos comparativamente con otros sectores de PDF se debía a que eran objeto cotidianamente de un control estricto y externo en la aplicación de las normas, reflejado en un procedimiento que comportaba varios niveles de firma para la aprobación de los permisos de trabajo ["].

Un Inspector de Seguridad de MRI señalaba a su vez que la clave, el "amuleto" [10] que garantizaba la seguridad, era el trabajo en equipo entre los supervisores de MRI (y de 
PDF) y los supervisores de los contratistas, para asegurar la presencia permanente de unos u otros en el terreno.

Procedimientos estrictos, supervisión redundante (trabajando en equipo), que se suman al "enfoque participativo" del Gerente de Construcciones de PDF, consistente en responsabilizar a los operarios, pero ofreciéndoles la capacitación necesaria, como lo reconocían ellos mismos - y sus supervisores - en sus testimonios.

\subsection{Ventajas e inconvenientes del status de contratado de estructura}

En un grupo focal en el que participaron 10 inspectores del Área de Proyectos (inspectores de seguridad, calidad, electricidad, cañerías, etc.) de la empresa MRI, los presentes se expresaron del modo siguiente en cuanto a las particularidades de la relación contractual que los vinculaba con PDF (es importante mencionar que el nivel de salarios - absoluto o comparado con el personal de PDF - nunca fue mencionado por los entrevistados como un problema).

\section{Cuadro 5: aspectos positivos y problemáticos del status de contratado de estructura}

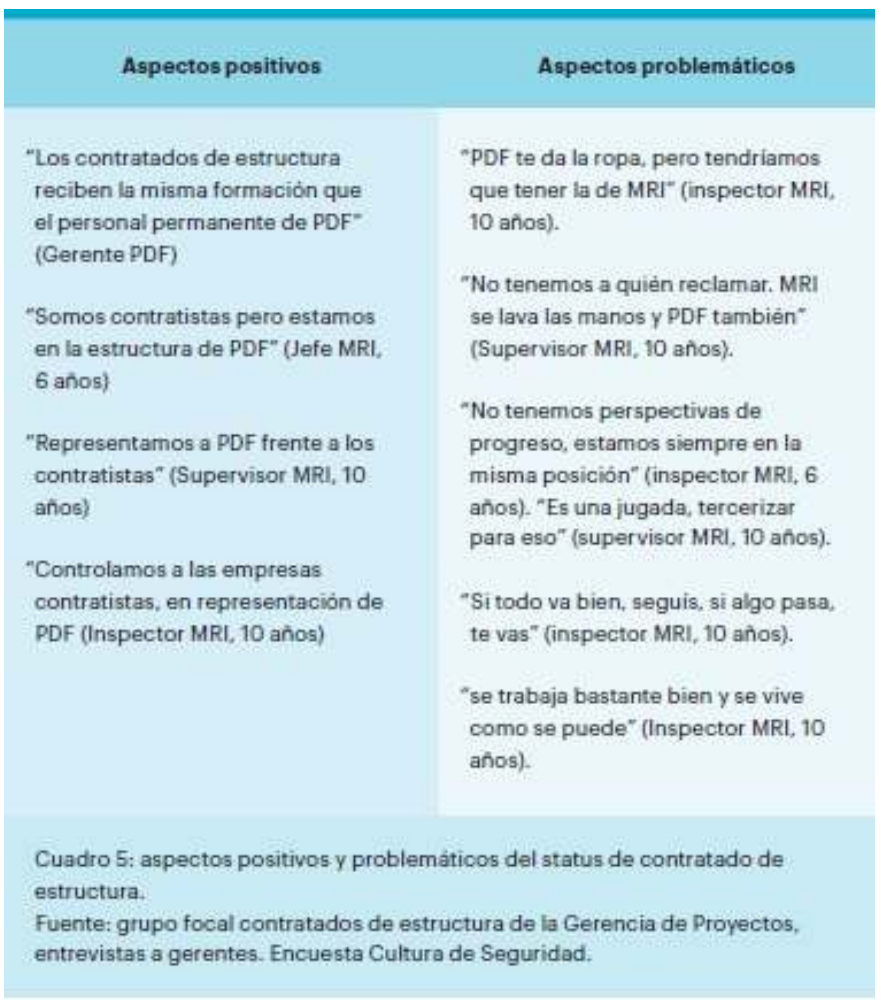

FUENTE: grupo focal contratados de estructura de la Gerencia de Proyectos, entrevistas a gerentes. Encuesta Cultura de Seguridad.

Como ya dijimos, los contratados de estructura de MRI ocupan una posición en la jerarquía de la organización donde trabajan (por eso se los denomina "de estructura"), que no es aquella que paga sus salarios (por eso se los llama "contratados", aunque fuesen empleados permanentes de MRI), representando a PDF ante los contratistas que realizan obras para ella. Esa integración en el organigrama de PDF implica beneficios, principalmente en materia de formación, pero también problemas, no sólo de identidad 
("tendríamos que tener la ropa de MRI") sino también en cuanto a oportunidades de carrera y de representación en caso de problemas ("no tenemos a quién reclamar"), lo cual se percibe como una estrategia destinada a debilitar su posición reivindicativa ("es una jugada") que limita la capacidad de reacción de los contratados de estructura al plano individual ("si algo pasa, te vas").

60 La declaración "se vive como se puede" es, en cambio, la punta del iceberg de problemas inherentes a la calidad de vida en el los campamentos. En la encuesta formulamos preguntas sobre riesgos para la salud que no se limitaban a los de carácter físico e incluían otros, como el stress y la ansiedad, que como se verá a continuación, aparecieron claramente enfatizados por los contratados de estructura.

\subsection{Una clara prevalencia de los riesgos psicosociales}

61 Cuando interrogamos al Director de Construcciones de PDF sobre los riesgos laborales que debía combatir nos mencionó los mismos riesgos tradicionalmente tenidos en cuenta en las estadísticas corporativas de frecuencia y gravedad de los accidentes - y por consiguiente en las políticas de seguridad - de ésta y otras grandes empresas del sector: "Son los riesgos físicos propios de la construcción en cualquier lugar o sitio, sumado a ellos el trabajo en áreas de proceso con peligros de incendio y explosión". Según los resultados de la encuesta de percepciones, esos riesgos "clásicos" se consideraban, sin embargo, satisfactoriamente controlados (con un índice de 6,3/10).

62 Además de la preocupación por la preservación del empleo - significativamente mayor, como podía esperarse, entre el personal de las empresas contratadas - los factores más importantes de riesgo para la salud identificados por quienes respondieron la encuesta eran los riesgos de carácter psicosocial, como el estrés y la ansiedad.

Cuadro 6: factores de riesgo para la salud, según tipos de relación contractual 
Nota: por debajo de 6,5 (insatisfactorio), de 6,5 a 7,5 (bueno), 7,5 y más (excelente)

\begin{tabular}{|c|c|c|c|c|}
\hline & 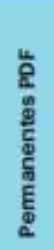 & 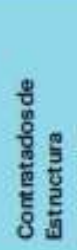 & 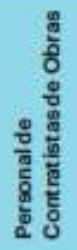 & $\begin{array}{l}\text { बु } \\
\frac{5}{8} \\
\frac{8}{8} \\
\frac{8}{2} \\
\frac{5}{2}\end{array}$ \\
\hline Uso de Equipos de Protección Individual & 8,3 & 8,4 & 7,9 & 8.2 \\
\hline Respeto de las normas de trabajo seguro & 7,0 & 7.7 & 7,5 & 7,4 \\
\hline Diseno del entorno de trabajo & 7.0 & 6.9 & 6,6 & 6,8 \\
\hline Gestion de los riesgos (fisicos) & 6.4 & 6,0 & 6,4 & 6,3 \\
\hline Informaciôn y formación de los empleados & 5.9 & 6,0 & 6,5 & 6,2 \\
\hline Estrés y presión & 4,5 & 5,9 & 6,1 & 5,6 \\
\hline Ansiedad & 5,6 & 5,7 & 5,4 & 5,5 \\
\hline Eficacia de las acciones de salud & 5.7 & 5,3 & 5,3 & 5,4 \\
\hline Preservación del empleo & 6,3 & 4,8 & 3,7 & 4,8 \\
\hline
\end{tabular}

FUENTE: Encuesta Cultura de Seguridad.

63 Como surge del cuadro anterior (que ordenamos de mejor a peor promedio general), no obstante la elevada antigüedad promedio del personal contratado de estructura y del personal de las empresas contratadas a cargo de las obras, la preocupación por la estabilidad del empleo los distinguía claramente del personal permanente de PDF.

En cuanto a la baja eficacia de las acciones de salud, uno de los aspectos que mayores reclamos suscitó luego en los grupos focales fue - como se verá en el próximo cuadro la ausencia de apoyo psicológico para hacer frente a los problemas de ansiedad.

El stress y la ansiedad eran, en efecto, un problema generalizado, que predominaba ampliamente sobre los riesgos de carácter físico (contaminaciones, incendios, explosiones, torceduras, etc.) en cuya reducción PDF no escatimaba esfuerzos ni inversión. El stress y la ansiedad afectaban sobre todo, sin embargo, al personal permanente de la empresa y, como se observa en el próximo cuadro, a los gerentes y jefes (sobre todo el estrés) más que a los supervisores y empleados. 
Cuadro 7: ansiedad y estrés, según niveles jerárquicos

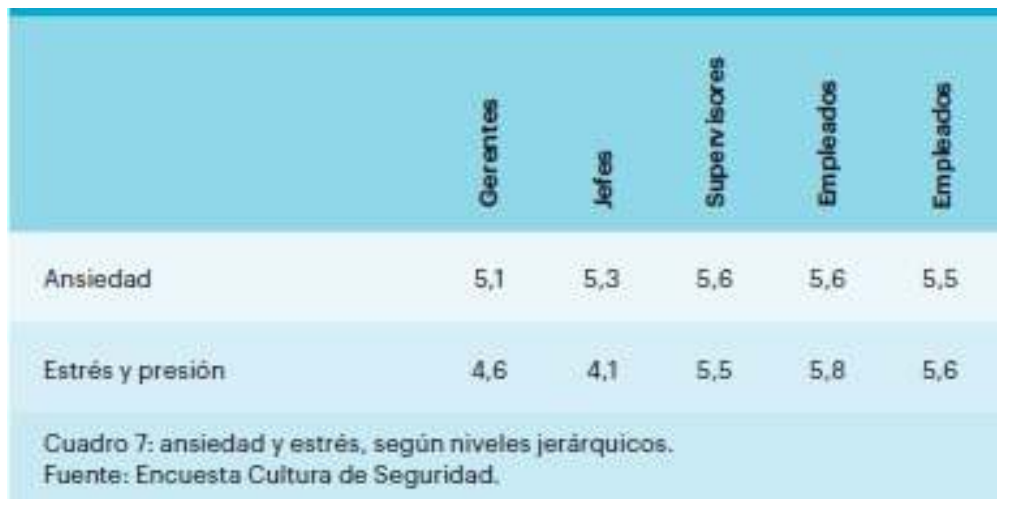

FUENTE: Encuesta Cultura de Seguridad

Llamativamente, la insatisfacción debida a los riesgos psicosociales nos fue planteada en forma catártica cuando evocamos el problema de la ansiedad revelado por la encuesta en la entrevista grupal que realizamos a los contratados de estructura, permanentes de la empresa MRI, que trabajaban en la Gerencia de Proyectos de PDF. ¿Por qué el problema surgió con tanta fuerza en esa entrevista grupal y no en otras, pese a lo generalizado del fenómeno?

67 Según nuestra hipótesis, sobre la cual volveremos más adelante, se debió a que la insatisfacción de los contratados de estructura era cotidianamente potenciada por las diferencias existentes de calidad de vida en el sitio entre ellos y los permanentes de "la empresa de enfrente", insatisfacción agravada por el contraste entre la falta de escucha por parte de PDF respecto a la manifestación de tales diferencias y la consciencia por parte de quienes los sufrían, de los buenos resultados que la Gerencia de Proyectos estaba logrando al "trabajar en equipo" bajo estándares de mayor exigencia (exagerada, según varios testimonios) con los supervisores y empleados de las empresas contratadas a cargo de las obras, gracias al rol clave desempeñado por los contratados de estructura. 


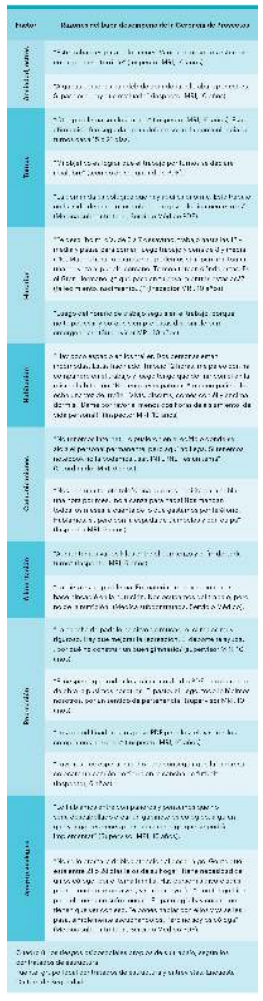

FUENTE: grupo focal contratados de estructura y entrevistas. Encuesta Cultura de Seguridad.

Los problemas sociales (como los repetidos divorcios) y de salud resultantes de lo anterior no eran consecuencia de cada tipo de problema individualmente sino de los círculos viciosos instaurados en su articulación, que derivaban por ejemplo en problemas de alcoholismo, obesidad y depresión, cuando no en problemas físicos no declarados como las lesiones en prácticas deportivas realizadas sin el adecuado contexto y supervisión, que luego se ocultaban para hacerlas pasar por accidentes laborales. En una situación como ésta, no llama la atención que concentrarse en el trabajo de cada día fuese considerado por muchos como una tranquilizadora evasión.

\subsection{La incomprensible manifestación de los riesgos psicosociales}

¿Cuál fue la reacción de los altos directivos de la filial cuando presentamos los resultados de la encuesta, dedicando un apartado especial a los riesgos psicosociales y la calidad de vida de los empleados de la empresa de enfrente?

Una diferencia común cuando se comparan las respuestas a la encuesta según niveles jerárquicos reside en la percepción comúnmente más favorable del funcionamiento del sistema de gestión de la seguridad por parte de los niveles más altos. Y una reacción inicial también habitual cuando a dicho contraste consiste en interpretar la diferencia como una consecuencia de que "se trata de percepciones de los operadores, no de la realidad objetiva". No resulta difícil explicar luego que la encuesta recoge percepciones también en el caso de los supervisores, los jefes y los gerentes. Comienza entonces un proceso de elaboración que generalmente culmina con el respeto de la percepción de los operadores y la realización de grupos focales para recoger explicaciones y sugerencias concretas de mejora. 
71 Pese a estar preparados para enfrentar ese tipo de reacciones, grande fue nuestra sorpresa por la que tuvo lugar cuando nos referimos - estimulados a hacerlo "sin complacencias" por el Director Corporativo de Seguridad de la multinacional- al conjunto de cuestiones que surgieron en el grupo focal de los contratados de estructura y en la entrevista a la médica contratada responsable del servicio médico del campamento.

72 El Director de Seguridad de la filial - a quien habíamos comentado previamente esos testimonios - simplemente los (des)calificó empleando para ello el término "bulshit". El Gerente de Operaciones a cargo de la seguridad en el campamento donde recogimos los testimonios afirmó: "cuando comencé a trabajar en este oficio hace treinta años sabía a lo que me atenía. Era muy difícil comunicarme con mi familia". Ante lo cual un gerente de la sede corporativa que había trabajado largo tiempo en el campamento, agregó: "El problema está en la selección del personal. Quienes no toleran éste tipo de trabajo no deberían ser admitidos".

73 No se trató entonces de una reacción natural de sorpresa ante el contraste de opiniones sino de un franco y tajante rechazo por parte de los principales responsables de la seguridad. Como si los problemas planteados fueran ininteligibles. ¿Por qué?

\section{Conclusión}

"Según el filósofo Heidegger, lo que menos vemos es nuestro par de anteojos" (Riveline, 2010)

74 ¿A qué se debió la reacción negativa de los altos directivos de PDF cuando reportamos ante ellos los testimonios de los contratados de estructura del Área de Proyectos? Según la metáfora que propone Heidegger, posiblemente obedeció a la invisibilidad de los anteojos utilizados en la empresa para observar los riesgos.

El Área de Proyectos era exitosa porque satisfacía los indicadores (KPI) clave utilizados para evaluar el funcionamiento del sistema de gestión y el desempeño de los gerentes. ¿Qué necesidad había entonces de replantear las condiciones de vida y/o el estatus de los contratados de estructura si el sector en el que trabajaban funcionaba tan bien y en forma tan satisfactoria para quienes eran evaluados en función de ello [11]? Cabe anotar que el desarrollo y la inclusión de indicadores sobre riesgos psicosociales en una empresa petrolera recién dio sus primeros pasos en una firma noruega vanguardista dos años después de la realización de nuestra encuesta (Vestly Bergh, Hinna, Leka, \& Jain, 2014).

76 Ahora retomemos las preguntas iniciales de la introducción: ¿Quién era Manuel y en qué consistía su status de contratado de estructura?

77 Desde un punto de vista conceptual, podemos caracterizar la categoría contratado de estructura como una "forma plural" (Bradach \& Eccles, 1989). Las formas plurales son formas híbridas resultantes de la combinación de tres tipos básicos de coordinación: el mercado, la jerarquía y la red. En este caso se trata de una red (de una empresa contratada) cuyo personal está literalmente embebido (embedded) en la jerarquía de PDF.

78 ¿A qué se debía la eficacia del Área de Proyectos, que tanto nos sorprendió dada la insatisfacción manifestada por sus miembros? Según Bradach y Eccles (op. cit), las 
combinatorias plurales permiten compensar los defectos de una forma de coordinación con las virtudes de otra forma de coordinación [12]. Asimismo, los buenos resultados del Área de Proyectos podían atribuirse al liderazgo participativo de su gerente fundador, empleado permanente de PDF que imprimió su estilo personal de gobierno al funcionamiento del área convirtiéndola en un punto de referencia (benchmark) interno. ¿A qué se debía la insatisfacción de los contratados de estructura sobre la calidad de vida en la parte del campamento en la cual habitaban y tenían su oficina? Si bien no reclamaban ser incorporados al plantel estable de PDF (deseaban por el contrario contar con ropa distintiva de MRI), la mayor exigencia a la cual eran sometidos [13], y el menor apoyo $\left.{ }^{[14}\right]$ y reconocimiento $\left[{ }^{15}\right]$ que comparativamente recibían por sus logros provocaban en ellos una gran insatisfacción, que según el modelo clásico de demandas/ control (Karasek, 1999), reforzado por el sentimiento de injusticia vis-à-vis de "la empresa de enfrente", eran la fuente de su ansiedad y su estrés.

Si esta hipótesis fuese correcta, ¿por qué entonces la ansiedad y el estrés afectaban también (cfr. cuadros 6 y 7) a los permanentes de "la empresa de enfrente"?

La respuesta a ésta pregunta se relaciona probablemente con el "estilo de vida" de los petroleros, muy bien caracterizado por el siguiente testimonio de un empleado permanente muy particular de PDF, un ingeniero-psicólogo, gerente de operaciones expatriado que se desempeñaba en otro de los campamento patagónicos de la empresa [16]: "El mayor problema en esta industria es que tenemos un sistema de trabajo desastroso para la vida familiar, y que ese problema se tapa con dinero. Es un tironeo permanente que provoca problemas psicológicos, un problema internacional específico de la profesión" [17].

El punto en común entre los problemas de relación familiar derivados del trabajo en largos turnos y los problemas de calidad de vida (habitación, alimentación, esparcimiento, comunicaciones) en los campamentos son, en efecto, los problemas de sociabilidad. Sociabilidad interna a la familia de cada trabajador y sociabilidad en la pequeña comunidad que son los campamentos y las plataformas offshore. En otras palabras, riesgos específicamente sociales, con consecuencias psicológicas como el estrés y la ansiedad que afectaban no solo a los contratados de estructura, y que no se resolvían mediante el pago de altos salarios relativos, es decir, monetizando la asunción de los riesgos psicosociales. Se comprende así el verdadero alcance que puede atribuirse al término "higiene" propuesto por Herzberg $\left[{ }^{18}\right]$, tan caro a los profesionales de la gestión de riesgos.

83 Esta conclusión es extrapolable conceptualmente $\left[20^{19}\right]$ al caso de otras profesiones que comparten con la petrolera el "estilo de vida" propio del trabajo en turnos largos y en comunidades aisladas, como sucede por ejemplo con los militares, los marineros, los mineros o la tripulación de los aviones y las misiones espaciales y, en el caso de los petroleros, con quienes trabajan en las plataformas offshore y los campamentos de tierra firme.

Desde un punto de vista metodológico, casos particulares como el analizado tienen valor especial cuando permiten realizar observaciones poco comunes, como sucedió con los estudios de la mente realizados gracias al empleado ferroviario Phineas Cage que sobrevivió doce años - con importantes cambios en su conducta - tras un accidente que sufrió en 1861 en el que perdió gran parte del lóbulo frontal de su cerebro (Damasio, Grabowski, \& Frank, 1994; Siggelkow, 2007). Dichas observaciones tuvieron lugar en nuestro caso durante la fase cualitativa de la encuesta, que nos permitió indagar flexible pero sistemáticamente sobre las cuestiones que emergieron en las 
entrevistas. Es importante remarcar además que la unidad de análisis del caso estudiado incluyó la empresa contratante y su red de subcontratistas, lo cual es una práctica inhabitual en las encuestas de éste tipo pese al altísimo grado de tercerización que caracteriza la actividad (no solo) de las grandes empresas petroleras, que en el caso de PDF involucraba al 71,2\% de las personas entrevistadas.

En cuanto a las posibles soluciones para los problemas constatados, fue fácil decir, como lo hicimos ante los directivos de la empresa, que las mejoras reclamadas por los contratados de estructura - extender la red de banda ancha, construir un gimnasio, contratar un psicólogo para el servicio médico... - podían realizarse a muy bajo costo y que el cambio podía facilitarse sin necesariamente modificar el status de los contratados de estructura si se suprimía, como sucedía en otros campamentos de la empresa, la escisión espacial de la oficina del Área de Proyectos. Tal vez el paciente tuviese razón al negarse a cambiar de anteojos.

En efecto, dos de los accidentes más graves de los últimos años en el ámbito petrolero (la gran explosión en la refinería de Texas City en 2005 y el escape masivo en el pozo petrolero del Golfo de México en 2010) han sido atribuidos por los investigadores al énfasis en la gestión a corto plazo (en los indicadores anualizados de incentivos basados en la tasa de frecuencia/gravedad de los accidentes laborales) que, combinada con la frecuente rotación de los directivos entre unidades de negocios, tuvo lugar en detrimento de la gestión de los riesgos operacionales o, en otros términos, de la prevención de los riesgos mayores (Hopkins \& Maslen, 2015). Como argumentan los autores citados, los eventos de este tipo son por definición infrecuentes, y la fragilización de las instalaciones debida al descuido de la gestión del riesgo operacional no necesariamente produce efectos inmediatos. El accidente catastrófico puede tardar años, en efecto, hasta abandonar el estado de latencia.

La franca aceptación de los aspectos negativos del estilo de vida petrolero hará posible aprovechar oportunidades que hoy están al alcance de la mano para mejorar sustantivamente la vida social, y por su intermedio la salud mental, la estabilidad familiar, la capacidad productiva y la seguridad laboral de los trabajadores de la profesión. Cuando recomendamos un ajuste en la graduación de los anteojos no estamos preconizando el descuido de los riesgos mayores. Por el contrario, nos parece necesario incorporar estos últimos a una agenda integrada, multifocal, de investigaciones y de acción.

\section{BIBLIOGRAFÍA}

Abramo, L., \& Abreu, A. (1998). “Um olhar de genero". Visibilizando precarizaçoes ao longo das cadeias productivas". In L. Abramo \& A. de Paiva Abreu (Eds.), Gênero e trabalho na sociologia Latinoamericana. Sào Paulo/Río de Janeiro: ALAST/SERT.

Bradach, J., \& Eccles, R. (1989). "Price, authority, and trust: From ideal types to plural forms." Annual Review of Sociology, 15, 97-118. 
Cantero, J. (2008). La gouvernance de la gestion des risques industriels : entre la sécurité et la performance économique. Le cas des plateformes chimiques rhône-alpines. Thèse pour l'obtention du titre de Docteur en Sciences de Gestion. Université Jean Moulin Lyon 3, France.

Damasio, H., Grabowski, T., \& Frank, R. (1994). “The return of Phineas Gage: clues about the brain from the skull of a famous patient." Science, 264(5162), 1102-1105.

Eisenhardt, K. (2008). “Generalization from qualitative inquiry.” In K. Ercikan \& R. Wolff-Michael (Eds.), Generalization from Educational Research. Beyond Qualitative and Quantitative Polarization (pp. 51-67). Taylor \& Francis.

Herzberg, F. (1968). “One more time. How do you motivate employees?" Harvard Business Review, $46(1), 53-62$.

Hopkins, A., \& Maslen, S. (2015). Risky Rewards. How company bonuses affect safety? Surrey, UK: Ashgate.

Hubinger, L., Parker, A. W., \& Clavarino, A. (2002). "The Intermittent Husband. Impact of home and away occupations on wives/partners." In Queensland Mining Industry Health and Safety Conference 2002 (pp. 81-91). Townsville, Australia.

Johnstone, R. (2005). "Regulating occupational health and safety in a changing labour market" (No. Working Paper 34). National Research for Occupational Health and .... Working Paper 34. The Australian National University. Canberra.

Johnstone, R., Mayhew, C., \& Quinlan, M. (2005). "Outsourcing Risk? The Regulation of Occupational Health and Safety Where Subcontractors are Employed." Comparative Labor Law and Policy Journal, 22, 351-394.

Karasek, R. (1999). "El modelo de demandas/control: enfoque social, emocional y fisiológico del riesgo de estrés y desarrollo de comportamientos activos." In OIT. Enciclopedia de salud y seguridad en el trabajo. OIT.

la Garza, E. De, \& Valdivia, J. M. (1998). Reestructuración y cambio en las relaciones laborales en la telefonía mexicana. In Privatización de las telecomunicaciones en América Latina. EUDEBA.

Lee, T. W. (1999). Using Qualitative Methods in Organizational Research. Organizational Research Methods Series. Sage publications. London.

Leite, M. (2003). Trabalho e sociedade em transformaçao. Mudanças produtivas e atores sociais. Sao Paulo: Fundaçao Perseu.

Lewis, J., Porter, M., \& Shrimpton, M. (1988). Women, work and family in the British, Canadian and Norwegian offshore oilfields. London: McMillan.

Mayhew, C., Quinlan, M., \& Ferris, R. (1997). "The effects of subcontracting/outsourcing on occupational health and safety: survey evidence from four Australian industries." Safety Science, 25(1), 163-178.

Morrice, J., \& Taylor, R. (1978). “Intermittent Husband Syndrome.” New Society.

Nossar, I., Johnstone, R., \& Quinlan, M. (2003). “Regulating supply-chains to address the occupational health and safety problems associated with precarious employment: The case of home-based clothing workers in Australia" (No. 21). Working Paper 31. National Research Centre for OHS Regulation. The Australian National University.

Parkes, K. (2002). Psychosocial aspects of work and health in the North Sea oil and gas industry. HSE Books. 
Parkes, K. (2010). Offshore working time in relation to performance, health and safety. Norwich, UK: RR772 Research Report. Health and Safety Executive.

Parkes, K., \& Byron, J. (2001). Psichosociological aspects of work and health in the UK oil and gas industry: a survey on onshore sites, and comparisons with offshore installations. Sudbury: HSE Books.

Parkes, K., \& Clark, M. (1997). Psichosociological aspects of work and health in the UK oil and gas industry. Part IV: The offshore environment in the mid-1990s: A survey of psychosocial factors. Sudbury: HSE Books.

Parkes, K., \& Razawi VI, T. (1996). "Psichosociological aspects of work and health in the North Sea oil and gas industry. Part II. A five-year follow up study (11990-1995) of offshore and onshore personnel. Sudbury: HSE books.

Quinlan, M., Mayhew, C., \& Bohle, P. (2001). The global expansion of precarious employment, work disorganization, and consequences for occupational health: a review of recent research. International Journal of Health Services, 31(2).

Riveline, C. (2010). “The prince's eye-glasses.” Gérer et Comprendre, (100).

Rousseau, D. M., \& Libuser, C. (1997). “Contingent Workers in High Risk Environments.” California Management Review, 39(2), 103-123. doi:10.2307/41165889

Siggelkow, N. (2007). "Persuasion with case studies." Academy of Management Journal, 50(1), 20-24.

Tazi, D. (2010). "Subcontracting, outsourcing of maintenance and safety: a literature review." Doc. ICSI. Retrieved June 2, 2014, from http://www.icsi-eu.org/docsi/en/subcontracting-outsourcingof-maintenance-and-safety-f29?id_cible=1

Vestly Bergh, L. I., Hinna, S., Leka, S., \& Jain, A. (2014). “Developing a performance indicator for psychosocial risk in the oil and gas industry." Safety Science, 62, 98-106. doi:10.1016/j.ssci.

2013.08.005

Walter, J. (2000). “Technological Adaptation and 'Learning by Cooperation'. A Case Study of a Successful Onshore Technology Transfer in Tierra del Fuego.” The Journal of Technology Transfer, 25(1), 13-22. doi:10.1023/A:1007878819270

Walter, J., Poy, M., \& Darmohraj, A. (2009). “L'agir en sécurité. Confiance, intelligence de la règle et coopération.” In I. de Terssac, Gilbert; Boissières (Ed.), La sécurité en action (pp. 207-223). Edit. Octarès.

\section{ANEXOS}

Cuadro 1: "antigüedad" del personal que se realiza actividades en PDF, según tipos de relación contractual (en valores absolutos)

\begin{tabular}{|l|l|l|l|l|l|l|l|l|l|}
\hline Tipo de Contrato/ antigüedad & \multicolumn{2}{|l|}{$\mathbf{1}$ año } & \multicolumn{3}{|l|}{$\mathbf{1}$-3 años } & \multicolumn{3}{|l|}{$4-10$ años } & \multicolumn{2}{l|}{$+\mathbf{1 0}$ años } & Total \\
\hline Permanentes PDF & 65 & 12,3 & 66 & 12,4 & 223 & 42,2 & 175 & 33,1 & 529 \\
\hline Contrat. de Estruct. & 51 & 8,8 & 88 & 15,1 & 278 & 48 & 164 & 28,2 & 581 \\
\hline Pers. de contratista & 155 & 21,3 & 117 & 16,1 & 334 & 46 & 120 & 16,5 & 726 \\
\hline
\end{tabular}




\begin{tabular}{|l|l|l|l|l|l|l|l|l|l|}
\hline Total & 271 & 15 & 271 & 15 & 835 & 45,5 & 459 & 25 & 1836 \\
\hline
\end{tabular}

Fuente: Encuesta Cultura de Seguridad.

Cuadro 2: tipos de contratos por área de PDF y niveles jerárquicos (en valores absolutos)

\begin{tabular}{|c|c|c|c|c|c|c|c|c|c|}
\hline & $\begin{array}{l}\text { produc- } \\
\text { ción }\end{array}$ & $\begin{array}{l}\text { manteni- } \\
\text { miento }\end{array}$ & $\begin{array}{l}\text { Proyec- } \\
\text { tos }\end{array}$ & $\begin{array}{l}\text { Extrac- } \\
\text { ción }\end{array}$ & $\begin{array}{l}\text { Logís- } \\
\text { tica }\end{array}$ & HSE & Otros & Totales & $\%$ \\
\hline PERMAN. PDF & 58 & 58 & 71 & 42 & 22 & 27 & 250 & 528 & 28,2 \\
\hline Empleados & 7 & 10 & 15 & 7 & 3 & 1 & 81 & 124 & 6,8 \\
\hline Supervisión & 38 & 28 & 30 & 21 & 10 & 20 & 92 & 239 & 13 \\
\hline Jefatura & 13 & 19 & 25 & 12 & 8 & 5 & 70 & 152 & 8,3 \\
\hline Gerencia & & 1 & 1 & 2 & 1 & 1 & 7 & 13 & 0,7 \\
\hline $\begin{array}{l}\text { CONTR. DE } \\
\text { ESTR. }\end{array}$ & 105 & 152 & 95 & 54 & 56 & 32 & 87 & 581 & 31,6 \\
\hline Empleados & 91 & 129 & 44 & 33 & 43 & 25 & 70 & 435 & 23,7 \\
\hline Supervisión & 13 & 23 & 51 & 20 & 13 & 6 & 17 & 143 & 7,8 \\
\hline Jefatura & 1 & & & 1 & & & & 2 & 0 \\
\hline Gerencia & & & & & & 1 & & 1 & 0 \\
\hline $\begin{array}{l}\text { CONTR. } \\
\text { OBRAS }\end{array}$ & 24 & 45 & 181 & 124 & 80 & 17 & 256 & 727 & 39,6 \\
\hline Empleados & 14 & 39 & 141 & 103 & 64 & 13 & 227 & 601 & 32,7 \\
\hline Supervisión & 9 & 6 & 37 & 21 & 15 & 4 & 28 & 120 & 6,5 \\
\hline Jefatura & 1 & & 2 & & 1 & & & 5 & 0 \\
\hline Gerencia & & & 1 & & & & & 1 & 0 \\
\hline Totales & 187 & 255 & 347 & 220 & 158 & 76 & 593 & 1836 & 100 \\
\hline
\end{tabular}

Fuente: encuesta Cultura de Seguridad.

\section{NOTAS}

1. En América Latina, la tercerización fue el principal medio para un "ajuste flexible de la cantidad de fuerza de trabajo según las necesidades de la producción y del mercado" (E De la 
Garza \& Valdivia, 1998: 203). Según las revisiones bibliográficas realizadas por Lais Abramo para el continente americano y por Marcia Leite para el caso brasileño, la situación laboral en las cadenas productivas se caracterizaba a fines de la última década del siglo pasado por la precarización del trabajo “...como consecuencia del uso intensivo de mano de obra mal pagada, el empleo de equipamientos obsoletos, la informalidad o la ausencia de contratos de trabajo, los bajos niveles de calificación y los métodos de gestión paternalistas o despóticos" (Abramo \& Abreu, 1998: 47), así como por el "...mantenimiento del trabajo repetitivo y descalificado, el aumento de los ritmos, la intensificación del control, las pérdidas de beneficios, la disminución de los niveles salariales, la precarización del empleo y la elevación de la incidencia de las dolencias profesionales" (Leite, 2003: 208).

2. El diseño del cuestionario lo realizamos en el marco de un convenio de cooperación entre el Centro de Investigaciones por una Cultura de Seguridad (CICS) de la Universidad de San Andrés en Argentina (http://www.udesa.edu.ar/Unidades-Academicas/Centros/Investigaciones-poruna-Cultura-de-Seguridad/El-centro) y el Institut pour une Culture de Sécurité (ICSI) de Toulouse, Francia (http://www.icsi-eu.org/fr/).

3. La recolección de los testimonios la efectuamos registrándolos dactilográficamente durante las reuniones. Para su análisis evaluamos la posibilidad de recurrir a software especializado en el análisis de datos cualitativos, pero optamos por un fichaje y una postcodificación realizados en forma manual. El volumen y la naturaleza del material recogido no justificaron esa forma de tratamiento.

4. Realizamos las mismas entrevistas en otro gran campamento de la empresa localizado en una región patagónica muy alejada de ésta. En dicho campamento el Area de Proyectos no estaba separado espacialmente ni en cuanto a la calidad de la construcción del resto de las oficinas administrativas y no se repitieron los mismos testimonios.

5. MRI es una empresa local prestataria de servicios de ingeniería, de alto nivel tecnológico. Según la página corporativa, su dominio principal de competencias es la operación de plantas químicas y la elaboración y comercialización de productos químicos. Entre sus objetivos secundarios menciona la investigación aplicada al desarrollo tecnológico, el diseño de ingeniería básica y de detalle, la construcción, el montaje, la puesta en marcha y el mantenimiento de instalaciones industriales así como la prestación de todo otro servicio relacionado con la actividad industrial, ya sea por cuenta propia o asociándose -como en PDF- a terceros. Además, en el momento de realización de la encuesta, declaraba poseer un sistema integrado de gestión según normas ISO 9001 y 14.001, y OHSAS 18001.

Se trataba, en suma, de una empresa de alto nivel tecnológico cuyo personal era competente para tomar a su cargo procesos centrales desde el punto de vista de la gestión de la seguridad en actividades extractivas, tales como la supervisión de las obras realizadas por subcontratistas.

6. Colocamos el término antigüedad entre comillas pues se refiere al tiempo que llevaban los trabajadores trabajando sin discontinuidad para PDF, aunque durante ese período hubiese cambiado la empresa que los contrataba.

7. MRI es la empresa de la cual provenían los Contratados de Estructura que se desenvolvían en las Gerencias de Mantenimiento y de Proyectos de PDF.

8. Seis años se refiere al tiempo que el empleado de MRI llevaba trabajando para PDF.

9. Este mismo tipo de autorizaciones lo observamos en un diagnóstico que realizamos en talleres de reparación de aviones de gran porte, donde la entrega de una reparación debía ser firmada por el operario/técnico a cargo de la tarea, autorizada por un supervisor de la empresa y, por último, validada también por un inspector de la autoridad regulatoria nacional presente en la planta.

10. Curioso calificativo alusivo a propiedades mágicas, para referirse a una herramienta de gestión. ¿Cuál es la magia que permite, en efecto, instaurar la cooperación entre -los supervisores de- la empresa contratante y la contratista? 
11. En una entrevista posterior a la realización de la encuesta que efectuamos a un Jefe del Área de Proyectos, empleado permanente de PDF con más de 20 años de antigüedad, lo interrogamos sobre la razón de ser de la categoría contratados de estructura. Su respuesta fue que "la categoría se creó porque se suponía que, por tratarse de proyectos, el Área sería estructuralmente inestable. Pero no fue así y en varias ocasiones se discutió en la empresa sobre la conveniencia de convertir a los contratados de estructura en personal permanente de PDF. La decisión nunca se tomó y no encuentro ningún motivo especial para que haya sido así".

12. Poseer el status de contratado de estructura consistía entonces en estar cuasi-integrado en la jerarquía de la organización. Gracias al mayor nivel de exigencia que pesaba sobre ellos en comparación con los empleados permanente, PDF obtenía muy buenos resultados de seguridad que distinguían el Área de Proyectos. Este argumento, planteado por los propios empleados de MRI en sus testimonios, era el que justificaba de hecho la no supresión de la categoría híbrida por parte de la dirección de PDF en éste y en otros sectores de la organización, aunque la antigüedad de quienes estaban adscriptos a ella fuese similar o aún superior a la del "personal estable" de la empresa.

13. "Como contratistas nos exigen cumplir todas las normas, en borrador o por aplicarse, a gusto y placer del personal jerárquico de PDF que esté de turno"; "además de nuestros propios controles la gente del sitio nos controla a fondo" (cfr. cuadro 4).

14. "Cuando los supervisores permanentes de PDF firman un permiso, se controlan a si mismos. Es muy difícil ser autocrítico con los errores de uno mismo"; "las exigencias de los permisos de trabajo siempre son mayores con nosotros que las que PDF tiene consigo misma. Tienen más contemplaciones internamente" (cfr. cuadro 4).

15. "No tenemos a quién reclamar", "no tenemos perspectivas de progreso" (cfr. cuadro 5).

16. Donde el Área de Proyectos no estaba escinda espacialmente de la administración de PDF, y en ningún momento se planteó el tema de "la empresa de enfrente". Volveremos sobre éste asunto al final de la introducción.

17. El autor de éste testimonio nos pidió reserva sobre su segundo título pues "podría ser mal visto por mis colegas ingenieros".

18. Según Herzberg "los factores de desarrollo o motivadores que son intrínsecos al trabajo incluyen la realización personal, el reconocimiento del logro, el trabajo mismo, la responsabilidad y el progreso o avance (en la carrera). Los factores que evitan la insatisfacción son factores de higiene extrínsecos al trabajo que incluyen la política y la gestión de la compañía, la supervisión, las relaciones interpersonales, las condiciones de trabajo, el salario, el nivel jerárquico y la seguridad (security)" (Herzberg, 1968), traducción y negrita nuestras).

19. Al decir esto distinguimos implícitamente la generalización teórica aquí propuesta y la generalización empírica (Eisenhardt, 2008).

\section{RESÚMENES}

Hay abundante literatura sobre el trabajo en largos turnos y la calidad de vida en los campamentos de tierra firme y las plataformas petroleras offshore y su impacto en la salud, la seguridad física y psicosociológica y la vida familiar de los trabajadores. El factor común del estilo de vida petrolero - y el de otras profesiones habituadas al trabajo en turno largo - reside, sin embargo, en los problemas de sociabilidad en el trabajo y en la vida personal. Llegamos a ésta conclusión, punto de partida para nuevas investigaciones, como corolario de una encuesta de 
percepciones sobre el funcionamiento del sistema de gestión de la seguridad de una empresa multinacional, en la cual profundizamos sobre dichos rasgos mediante entrevistas y grupos focales, en la cual - hecho inhabitual en éste tipo de diagnósticos - participó el personal de empresas contratadas, cuyos testimonios nos orientaron en esa dirección.

Existe abundante literatura sobre o trabalho em turnos longos e a qualidade de vida nos campos e plataformas offshore e seu impacto na saúde, segurança físico e psico-sociológica e vida familiar dos trabalhadores. O fator comum do estilo de vida dos trabalhadores petrolíferos - e dos trabalhadores de outras profissões acostumados a trabalho por turnos largos - reside, no entanto, os problemas de sociabilidade no trabalho e na vida pessoal. Chegamos a esta conclusão, o ponto de partida para novas pesquisas, como corolário de uma pesquisa de perceção em que nos aprofundarmos sobre esses recursos por meio de entrevistas e grupos focais - um fato que eu incomum neste tipo de diagnósticos - empresas participadas contrataram pessoal cujos testemunhos nos apontam nessa direção.

Il y a une abondante littérature sur le travail posté de longue durée et la qualité de la vie dans les champs pétroliers onshore et les plateformes pétrolières offshore et ses impacts sur la vie au travail - santé, sécurité - et la vie hors travail des travailleurs -impacts psychosociologiques et sur la vie familiale. Le facteur commun du style de vie propre à ce métier - et à celui d'autres professions habituées aux horaires postés de longue durée - réside dans les problèmes de sociabilité à la fois dans le travail et dans la vie personnelle hors travail. Ceci a été la conclusion, et le point de départ de nouvelles recherches, des résultats d'une enquête sur la perception du fonctionnement du système de gestion de la sécurité d'une entreprise multinationale. Dans ce cadre nous avons pu approfondir cet aspect par le biais d'entretiens individuels et collectifs, auxquels ont participé - fait inhabituel dans ce genre de diagnostics - le personnel des entreprises sous-traitées, dont les témoignages nous ont orienté dans cette direction.

There is abundant literature regarding long-shifts work and the quality of life in onshore oil camps and offshore platforms and their impact on the health and the physical and psychosociological safety and the family life of workers. The common factor of the life style of oil workers - and other professions accustomed to long shift works - lies, however, in sociability problems at work and in personal life. We reached this conclusion, the starting point for further research, from a perceptions survey in which we inquired on these features through interviews and focus groups where - an unusual fact in this kind of surveys - the staff of subcontracting companies participated and whose testimonies pointed us in this direction.

\section{ÍNDICE}

Palabras claves: campamentos petroleros, riesgos psicosociales, calidad de vida, subcontratación

Keywords: oil camps, psychosocial risks, quality of life, outsourcing

Mots-clés: champs pétroliers, risques psychosociaux, qualité de vie, sous-traitance

\section{AUTOR}

\section{JORGE WALTER}

Centro de Investigaciones por una Cultura de Seguridad, Escuela de Administración y Negocios, Universidad de San Andrés, Vito Dumas 284, B1644BID Victoria, Buenos Aires, Argentina walter@udesa.edu.ar 